randomly selected respondents demonstrated that it was feasible to collect such data, that there were very few respondents who refused to answer questions, and respondents provided data that was consistent with both the international literature and locally available data. ${ }^{9}$ These pilot study results contributed to funding being awarded for a large national survey of sexual health behaviour using the methodology of the NSW Health Survey. ${ }^{10}$

\section{CONCLUSIONS}

The quality of the data collected in the NSW Health Survey, and the convenience of having the data already analysed, is of great value to local area health service staff who do not have the resources to collect similar data. It indicates the maturity of the NSW public health system. I await the next round of data to assess changes, and to develop new area-specific questions to support emerging local priorities.

\section{REFERENCES}

1. Public Health Division. Report on the 1997 and 1998 NSW Health Surveys. NSW Department of Health, Sydney, 2001.

2. Public Health Division. Report on the 1997 and 1998 NSW Health Surveys. NSW Department of Health, Sydney, 2000.

3. Rissel C, Winchester L, Hodge W, Puech M, Gupta L, Ward J. Health outcome indicators for Central Sydney (1996).
Camperdown: Needs Assessment \& Health Outcomes Unit, Central Sydney Area Health Service, 1996.

4. Health Promotion Unit. Into the 21st Century-Strategic Directions for Health Promotion 2000-2005. Camperdown: Central Sydney Area Health Service, 2001.

5. Rissel C, Hua M, Mansfield A, Burgess G. The second CSAHS tobacco control plan: 1999-2004. Camperdown: Central Sydney Area Health Service, 1999.

6. Merom D, Rissel C. Factors associated with smoke-free homes in NSW: results from the 1998 NSW Health Survey. Aust N Z J Public Health 2001; 25(4): 339-345.

7. Bedford K, Wen LM, Hua M, Rissel C. 'Smoke near me and I smoke too': Evaluation of a smoke-free homes program in Central Sydney, NSW. Paper presented at the 1st National Tobacco Control Conference, June 12-15 2001, Adelaide.

8. Muscatello D, Rissel C, Szony G. Urinary symptoms and incontinence in an urban community: prevalence and associated factors in older men and women. Internal Medicine Journal 2001; 31:151-160.

9. Proude E, Rissel C. New sexual partners and condom use in Central Sydney-results from the 1997 NSW Health Survey. Health Promotion Journal of Australia 2001; 12(2): 140143.

10. Smith A, Rissel C, Richter J, Grulich A. Australian Study of Health and Relationships. La Trobe University, Central Sydney Area Health Service, and the University of New South Wales; www.latrobe.edu.au/ashr. Accessed 19 June 2001.

\title{
USING NSW HEALTH SURVEY DATA FOR ECONOMIC ANALYSIS
}

\author{
Marion Haas \\ Centre for Health Economics Research and Evaluation \\ University of Sydney
}

Economics is the study of how resources are allocated in order to produce commodities (that is, goods or services) which people need or desire. It builds on theories about how individuals or groups behave when faced with choices. Thus, the activities or behaviours economists are interested in understanding and evaluating are:

- production (that is, the resources or inputs used);

- consumption (that is, the commodities or outputs that are of value to consumers). ${ }^{1}$

In economic terms, health and health improvement are commodities produced by combining inputs such as the time and knowledge of individual consumers, healthy food, exercise, the time and skills of health care professionals, drugs, and health care facilities. The process of using inputs to produce outputs is termed the 'production function'. Economic analysis is used to examine the 'production function' in order to enhance the efficient production of goods and services. With respect to health care, the goal of economic analyses is to investigate the extent to which interventions, services, or programs meet the efficiency and equity objectives of the health care system.

\section{HOW CHERE USES NSW HEALTH SURVEY DATA}

During 2000-2001, the Centre for Health Economics Research and Evaluation (CHERE) has been using data from the NSW Health Surveys 1997 and 1998, and the 1999 Older People's Survey, to explore and understand issues such as the prevalence of risk factors, health care provision, access, and utilisation. These data have allowed us to analyse the way in which inputs (for example, the provision of breast screening services) contribute to outputs (for example, the utilisation of breast screening services). Of course, there are other factors that affect the production function in health care. Providing breast screening services is no guarantee that those who have most to gain from using them will do so. Therefore, any economic analysis must also take account of personal (for example, socioeconomic status and age) and demographic factors (for example, place of residence), as well as any geographic or organisational differences in the way services are provided (for example, equity of access). The remainder of this article describes a number of proposed 
or current projects in which NSW Health survey data are being used by CHERE.

\section{Breast Cancer Screening}

A paper entitled 'Systematic variations in breast screening utilisation in NSW: a comparison of needs-based and demand-based programs' was presented at the International Health Economics Association Conference held in York, England, at the end of July 2001. In that paper, we explore the distribution of breast screening in New South Wales. Women aged 50-69 are targeted as high risk and in need of screening every two years. Women aged 40-49 and 70-79 are eligible for screens if demanded. Using the NSW Health Survey data, we have addressed the following questions:

- Is breast screening among targeted women significantly associated with socioeconomic status (SES)?

- Does the association between screening and socioeconomic status differ significantly between areas?

- Is socioeconomic status less important in explaining differences in screening in high risk groups than in other groups?

The results show that, although being in the lowest SES quintile appears not to affect the overall likelihood that women in the targeted group will be screened, it does affect the likelihood of screening among women living in rural areas. In addition, there are significant variations in screening rates among women from different area health services, and between women born in Australia and those born overseas.

\section{Utilisation of general practitioner services}

The primary aim of this study, for which a project grant application has been submitted to the National Health and Medical Research Council, is to examine the frequency and quantity of use of general practitioner services among various groups in society, with particular focus on NSW. The study will investigate any systematic differences in use of general practitioner (GP) services among various socioeconomic groups, rural and metropolitan residents, and people of different selfperceived health needs, by combining data from the NSW Health Survey and other secondary sources. The analysis will test two null-hypotheses:

- the probability and level of utilisation of GP services in a fixed period are independent of self-assessed health status;

- the relationship between the level of utilisation of GP services and self-assessed health status is independent of socioeconomic status, region, ethnicity, Aboriginal and Torres Strait Islander background, and social support.

The results of the study aim to provide an updated representation of GP utilisation using the 1997-98 NSW Health Survey and will also utilise the 1995 and 2001(when available) National Health Surveys. The study aims to develop a model of GP utilisation that will allow examination and testing of a number of variables, including any interactions.

\section{Privately insured people}

In our work with a private health insurance company, CHERE has used data from the NSW Health Survey to examine various aspects of health status, including risk factors for diabetes and cardiovascular disease, and utilisation of health services among privately insured people in NSW. The results have been used to inform the development of models of costs and benefits for the company. They have also been used in the development of disease management strategies for people with diabetes.

\section{NSW Older People's Survey}

Our work using data from the NSW Older People's Survey is at a preliminary stage. We are currently examining all the variables used in the survey, in particular those concerned with socioeconomic status, utilisation of health and care and other services, and burden of care, before developing a set of questions around the efficiency and equity of health care for older people in general, and for groups within the population of older people (for example, women, men, people from non-English speaking backgrounds, people from lower socioeconomic backgrounds, and people living in rural or remote parts of NSW).

\section{CONCLUSION}

Economic analyses of health care can inform policy, particularly in the context of planning and priority setting for new or altered services. Such analyses are driven by economic theory that produces hypotheses able to be tested using data such as those from the NSW Health Survey. To maximise the usefulness of any economic analysis it is essential to collect relevant socioeconomic and sociodemographic data about such factors as income, employment, occupation, education and housing.

\section{REFERENCE}

1. Cohen DR, Henderson JB. Health, Prevention and Economics. Oxford: Oxford University Press, 1991. 